\title{
NOTES
}

\section{1,5-Dichlorohexamethyltrisiloxane as a Modifier of Membranes of Oligosiloxane-Containing Polyamides}

\author{
Toshiki Aoki, ${ }^{*}$ Yoshihiro Yamamoto, Kyoung-han SHIN, \\ and Eizo OiKaWA \\ Department of Material and Chemical Engineering, Faculty of Engineering, \\ Niigata University, Ikarashi 2-8050, Niigata 950-21, Japan \\ (Received July 24, 1992)

\begin{abstract}
KEY WORDS 1,5-Dichlorohexamethyltrisiloxane / Membrane / Modifier / Oligosiloxane-Containing Polyamide / Membrane Processability / Oxygen Permselectivity /
\end{abstract}

For a gas permeable membrane, it is absolutely necessary for the membrane to resist a pressure difference in permeation. When a new polymer which is designed and synthesized for a highly gas-permeable membrane does not have membrane processability, its permeability can not be measured. Then, cross-linking and a composite membrane have been used by many membrane researchers in order to enhance the membrane processability. However, the resulting cross-linkedmembranes usually become significantly lowpermeable and completely insoluble and the permeability coefficient of a composite membrane cannot be determined because their thickness and area of the membrane cannot be estimated precisely.

This paper describes the efficient improvement of the membrane processability of oligosiloxane-containing polyamides $(1,2)$ by treating with 1,5-dichlorohexamethyltrisiloxane (3) without insolubilization and the oxygen permeation behavior of the modified membranes.

\section{EXPERIMENTAL}

\section{Materials}

1,3-bis(3-aminopropyl)tetramethyldisilox- ane was kindly supplied by Toray Dow Corning Silicone Co. 2,5-Pyridinedicarbonyl chloride was synthesized from 2,5-pyridinedicarboxylic acid. ${ }^{1}$ 1,5-Dichlorohexamethyltrisiloxane (3) was synthesized from hexamethylcyclotrisiloxane. $^{2}$ KE-42TS of Shinetsu Silicone, Inc. was used for cross-linked polydimethylsiloxane (PDMS) membrane.

\section{Synthesis of the Polyamides $(\mathbf{1}, \mathbf{2})$}

A solution of 2,5-pyridinedicarbonyl chloride $1.43 \mathrm{~g}(7.04 \mathrm{mmol})$ in chloroform $(2.5 \mathrm{ml})$ was added dropwise at $0^{\circ} \mathrm{C}$ to a solution of 1,3-bis(3-aminopropyl)tetramethyldisiloxane $1.75 \mathrm{~g}(3.04 \mathrm{mmol})$ and triethylamine $1.45 \mathrm{~g}$ $(14.3 \mathrm{mmol})$ in chloroform $(2.5 \mathrm{ml})$. After stirring for $18 \mathrm{~h}$ at room temperature, the solution was poured into diethylether. The precipitate was washed with water and was reprecipitated from chloroform to diethylether. The polymer (1) was dried in vacuo for $24 \mathrm{~h}$ to give a slightly yellow powdery polymer in a $2.05 \mathrm{~g}(76.5 \%)$ yield. ${ }^{1} \mathrm{H} \mathrm{NMR}\left(\mathrm{CDCl}_{3}, \mathrm{ppm}\right)$;
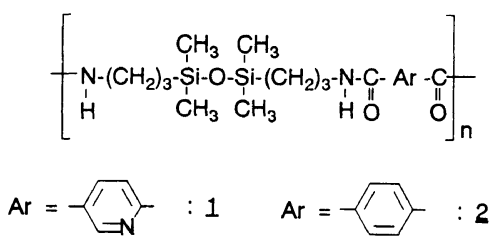
$\delta-0.10\left(12 \mathrm{H}, \mathrm{s}, \mathrm{SiC}_{3}\right), 0.34\left(4 \mathrm{H}, \mathrm{b}, \mathrm{SiC}_{2}\right)$, $1.50\left(4 \mathrm{H}\right.$, b, $\left.\mathrm{CH}_{2} \mathrm{CH}_{2} \mathrm{CH}_{2}\right), 3.29(4 \mathrm{H}, \quad b$, $\left.\mathrm{CONHCH}_{2}\right), 8.01,8.37(3 \mathrm{H}, 2 \mathrm{~b}$, pyridine ring protons), $9.42(2 \mathrm{H}, \mathrm{s}, \mathrm{CON} \underline{\mathrm{H}})$, where $\mathrm{b}$ means a broad peak. IR $\left(\mathrm{KBr}, \mathrm{cm}^{-1}\right) ; 1644(\mathrm{C}=\mathrm{O})$, $1538(\mathrm{~N}-\mathrm{H}), 1256\left(\mathrm{SiCH}_{3}\right), 1060(\mathrm{SiO}) .2$ was prepared similarly to the manner above.

Other characterizations are summarized in No. 1 and 8 of Tables I and II.

Modification of the Polyamides (1,2) by 1,5Dichlorohexamethyltrisiloxane (3)

On Casting (Membrane Preparation). A chloroform solution $(10 \mathrm{wt} \%)$ of the polyamide $(0.065 \mathrm{~g})$ containing $15-30 \mathrm{~mol} \%$ of 3 was cast on a polytetrafluoroethylene sheet. The solvent was evaporated for $12 \mathrm{~h}$ and the resulting membrane was dried in vacuo for $24 \mathrm{~h}$. Characterizations of these membrane polyamides are summarized in Tables I and II.

In the case of a laminated membrane, an

Table I. Characteristics of the siloxane-containing polyamide membranes treated with $3^{\text {a }}$

\begin{tabular}{|c|c|c|c|c|c|}
\hline \multirow{2}{*}{ No. } & \multirow{2}{*}{ Polyamide } & 3 added $^{\mathbf{b}}$ & $\eta_{\mathrm{sp}} / C^{\mathrm{c}}$ & $M_{w}^{\mathrm{d}}$ & \multirow{2}{*}{$M_{w} / M_{n}^{\mathrm{d}}$} \\
\hline & & $\mathrm{mol} \%$ & $\mathrm{dl} \mathrm{g}^{-1}$ & $\times 10^{3}$ & \\
\hline 1 & 1 & 0 & 0.13 & 7.86 & 2.06 \\
\hline 2 & 1 & 15 & 0.16 & 8.79 & 2.18 \\
\hline 3 & 1 & $17^{e}$ & 0.27 & 13.8 & 2.10 \\
\hline 4 & 1 & 20 & 0.17 & 10.6 & 2.04 \\
\hline 5 & 1 & 25 & 0.19 & 11.4 & 2.05 \\
\hline 6 & 1 & 30 & 0.19 & 11.8 & 2.09 \\
\hline 7 & 1 & $30^{f}$ & 0.24 & 13.2 & 2.10 \\
\hline 8 & 2 & 0 & 0.22 & 4.82 & 2.31 \\
\hline 9 & 2 & 15 & 0.24 & 5.91 & 2.10 \\
\hline
\end{tabular}

a 3 was added to 1 or 2 membrane $(0.065 \mathrm{~g})$ on casting in the air. For the code see Equations 1 and 2.

b The ratio of $\mathbf{3}$ to $\mathbf{1}$ or $\mathbf{2}$ based on a monomer unit.

c Measured at a concentration of $0.2 \mathrm{gdl}^{-1}$ in DMF at $25^{\circ} \mathrm{C}$.

d Determined by GPC correlated to standard polystyrene.

e $20 \mathrm{~mol} \%$ of 3 was added on casting in nitrogen, and after Soxhlet extraction with hexane $17 \mathrm{~mol} \%$ of 3 remained.

f $13 \mathrm{~mol} \%$ of 3 derivatives that were extracted from No. 4 membrane was added to No. 3 membrane. ethanol solution $(10 \mathrm{wt} \%)$ of the polyamide was cast on a cross-linked polydimethylsiloxane membrane.

In Solution. To a chloroform solution $(10 \mathrm{wt} \%)$ of $1(0.239 \mathrm{~g})$ was added $20 \mathrm{~mol} \%$ (based on a monomer unit) of $3(0.0364 \mathrm{~g})$ in the air (A) or in nitrogen (B) and stirring was continued for $1 \mathrm{~h}$. After the solution was poured into hexane, the precipitate was washed with hexane using Soxhlet extractor.

The resulting polymer was dried in vacuo for $24 \mathrm{~h}$. (A) Yield $0.251 \mathrm{~g}, 30 \%$ of 3 reacted with 1. (B) Yield $0.270 \mathrm{~g}, 85 \%$ of 3 reacted with 1 . ${ }^{1} \mathrm{H} \mathrm{NMR}\left(\mathrm{CDCl}_{3}, \mathrm{ppm}\right) ; \delta(\mathrm{A})-0.01(15 \mathrm{H}, \mathrm{b}$, $\left.\mathrm{SiC}_{3}\right), 0.42\left(4 \mathrm{H}, \mathrm{b}, \mathrm{SiC}_{2}\right), 1.42,1.54(4 \mathrm{H}$, b, $\left.\mathrm{CH}_{2} \mathrm{CH}_{2} \mathrm{CH}_{2}\right), 3.12\left(0.5 \mathrm{H}, \mathrm{b}, \mathrm{CONSiC} \underline{H}_{2}\right)$, $3.31\left(3.5 \mathrm{H}, \mathrm{b}, \mathrm{CONHC} \underline{H}_{2}\right), 7.98,8.34(3 \mathrm{H}$, $\mathrm{m}$, pyridine ring protons), $8.6-9.6(1 \mathrm{H}, \mathrm{s}$, $\mathrm{CON} \underline{\mathrm{H}})$; (B) $-0.01\left(18 \mathrm{H}, \mathrm{b}, \mathrm{SiC}_{3}\right), 0.42(4 \mathrm{H}$, b, $\left.\mathrm{SiC}_{2}\right), 1.42,1.54\left(4 \mathrm{H}, \mathrm{b}, \mathrm{CH}_{2} \mathrm{CH}_{2} \mathrm{CH}_{2}\right)$, $3.12\left(1.1 \mathrm{H}, \mathrm{b}, \mathrm{CONSiC} \underline{\mathrm{H}}_{2}\right), 3.30(2.9 \mathrm{H}, \mathrm{b}$, CONHCH$\left.{ }_{2}\right), 7.98,8.34(3 \mathrm{H}, \mathrm{m}$, pyridine ring protons), $8.6-9.6(1 \mathrm{H}, \mathrm{s}, \mathrm{CON} \underline{\mathrm{H}})$.

\section{Measurement of Oxygen Permeation Behavior}

Oxygen and nitrogen permeability coefficients $\left(P_{\mathrm{O}_{2}}\right.$ and $P_{\mathrm{N}_{2}}: \mathrm{cm}^{3}(\mathrm{STP}) \mathrm{cm}^{2} \mathrm{~cm}^{-1}$ $\mathrm{s}^{-1} \mathrm{~cm} \mathrm{Hg}^{-1}$ from upstream at atmospheric pressure to downstream in vacuo were measured by gas chromatographic method using YANACO GTR-10. Diffusion constants $\left(D_{\mathrm{O}_{2}}\right.$

$$
\begin{array}{ccc}
\mathrm{CH}_{3} & \mathrm{CH}_{3} & \mathrm{CH}_{3} \\
\mathrm{Cl}-\mathrm{Si}-\mathrm{O}-\mathrm{Si}-\mathrm{O}-\mathrm{Si}-\mathrm{Cl} \\
\stackrel{1}{\mathrm{I}}-\mathrm{Cl}_{3} & \mathrm{CH}_{3} & \mathrm{CH}_{3}
\end{array}
$$

\begin{tabular}{|c|c|c|c|}
\hline \multirow{2}{*}{$\begin{array}{c}\text { Membrane } \\
\text { polymer }\end{array}$} & 3 added $^{b}$ & $T_{\mathrm{g}}$ & $T_{\mathrm{m}}$ \\
\hline & $\mathrm{mol} \%$ & ${ }^{\circ} \mathrm{C}$ & ${ }^{\circ} \mathrm{C}$ \\
\hline 1 & 0 & 13.0 & 158 \\
\hline 2 & 15 & -8.0 & - \\
\hline 4 & 20 & -28.0 & - \\
\hline 6 & 30 & -29.5 & - \\
\hline
\end{tabular}

Table II. DSC data of the selected polyamides

a Numbers correspond to those in Table I.

b The ratio of $\mathbf{3}$ to $\mathbf{1}$ based on a monomer unit. 
and $D_{\mathrm{N}_{2}}: \mathrm{cm}^{2} \mathrm{~s}^{-1}$ ) were determined by time-lag method. Solubility coefficients $\left(S_{\mathrm{O}_{2}}\right.$ and $S_{\mathrm{N}_{2}}$ : $\mathrm{cm}^{3}$ (STP) $\mathrm{cm}^{-3} \mathrm{~cm} \mathrm{Hg}^{-1}$ ) were calculated using $S=P / D$. In the case of a laminated membrane, $P$ and $D$ were estimated by series model equation. ${ }^{3}$

\section{Measurements}

For GPC measurements, a Hitachi 655A-11 Liquid Chromatograph was used. ${ }^{1} \mathrm{H}$ NMR spectra were recorded on a Varian Gemini $200 \mathrm{H}(200 \mathrm{MHz})$ NMR spectrometer. Thermal analysis was made on a Shimadzu DSC-50. Elongations at a break were measured by using a TOM-5 of Minebea Co.

\section{RESULTS AND DISCUSSION}

\section{Improvement of the Membrane Processability}

The solvent-cast membrane from the polyamide $(\mathbf{1}, 2)$ was so brittle that it was unable to resist an $1 \mathrm{~atm}$ pressure difference in oxygen permeation.

However, when the solutions of $\mathbf{1}$ and $\mathbf{2}$ were cast in the presence of $15-30 \mathrm{~mol} \%$ (based on a monomer unit) i.e., $11-22 \mathrm{wt} \%$ of 1,5-dichlorohexamethyltrisiloxane (3), the resulting membranes were tough enough to resist a pressure difference of $1 \mathrm{~atm}$. The elongation at break of 2 increased from $104 \%$ to $652 \%$. (The measurement of the elongation at break of 1 was impossible because of its high hygroscopicity.) In addition, it is noted that these modified polyamide membranes were soluble in various solvents, i.e., chloroform, tetrahydrofuran, methanol, ethanol, $N, N$-dimethylformamide (DMF), $N, N$-dimethylacetamide, dimethyl sulfoxide, and $N$-methyl-2-pyrrolidone similarly to 1 and $\mathbf{2}$ membranes without $\mathbf{3}$, so that they can be readily characterized by GPC and NMR. The addition of a cross-linking agent to a polymer generally makes the polymer insoluble, whereas the addition of $\mathbf{3}$ kept solubility property of 1 and 2 unchanged.

Addition of hexamethylene diisocyanate, diiodomethane, dimethyldichlorosilane, and dimethylsilanediol as a cross-linking agent and hexamethyldisiloxane, octamethyltrisiloxane, hexamethylcyclotrisiloxane, and polydimethylsiloxane as plasticizing agent to 1 showed no effect on the improvement of the processability of 1 membrane. Only 3 among the compounds described above was capable of improving reproducibly the processability of $\mathbf{1}$ without insolubilization.

In order to investigate the reason for the effect of 3, these membrane polymers were characterized (Table I). By the addition of $\mathbf{3}$ all the average molecular weights and specific viscosities of 1 and $\mathbf{2}$ increased (No. 1 and 2-7, No. 8 and 9), indicating that 3 reacted with functional groups such as amido groups, amino groups, or carboxylic acid groups of $\mathbf{1}$ and $\mathbf{2}$. Since in these modified polyamides no insoluble part was observed, cross-linking did not occur. Therefore, one of the reason for the enhancement of the membrane processability is the increase of molecular weight.

Since 3 can react with water in the air and self-condense to yield oligodimethylsiloxane $\left(3^{\prime}\right)$ in these membranes, plasticizing effect by $3^{\prime}$ can be one of the reason for the improvement of the processability. In order to investigate this effect, unconverted 3 and its coexisting derivatives $\left(\mathbf{3}^{\prime}\right)$ in the membranes, which may function as a plasticizing agent, were removed by reprecipitation into hexane and subsequent Soxhlet extraction with hexane. As described in the experimental part, it was found that $30 \mathrm{~mol} \%$ (i.e., $6 \mathrm{~mol} \%$ based on a monomer unit) of 3 added reacted with 1 and $17 \mathrm{~mol} \%$ (i.e., $14 \mathrm{~mol} \%$ based on a monomer unit) did not reacted (No. 4 in Table I) in the air. In the case of the addition of $20 \mathrm{~mol} \%$ in nitrogen (No. 3 in Table 1), $85 \mathrm{~mol} \%$ (i.e., $70 \mathrm{~mol} \%$ based on a monomer unit) of $\mathbf{3}$ was found to react. The average molecular weight of 1 modified with 3 of No. 3 was higher than that of No. 4 (This fact indicates that in the absence of water the reaction proceeded more efficiently.). However, No. 3 membrane was brit- 
tle but No. 4 one was tough. When $13 \mathrm{~mol} \%$ (based on a monomer unit) of $\mathbf{3}^{\prime}$ that were extracted from No. 4 membrane was added to the No. 3 membrane from which unreacted 3 and $\mathbf{3}^{\prime}$ have been removed, the membrane became tough (No. 7). However, No. 1 membrane did not become tough by the addition of $3^{\prime}$. Therefore the improvement of the membrane processability is due to both the enhancement of the molecular weight by the reaction of 3 with 1 and the plasticization by $3^{\prime}$.

Since a $\mathrm{CH}_{2} \mathrm{NHCO}$ peak ( $\left.\delta 3.31 \mathrm{ppm}\right)$ was separated to 3.12 and 3.31 and the area of a $\mathrm{CON} \underline{H}$ peak at $9.42 \mathrm{ppm}$ decreased in ${ }^{1} \mathrm{H}$ NMR spectra of No. 3 and No. 4 compared with that of No. 1, a part of amido groups of 1 was found to react with 3. Amino groups and carboxylic acid groups at the chain ends of $\mathbf{1}$ also may react with 3 but the reaction could not be confirmed by ${ }^{1} \mathrm{H}$ NMR. These results indicate that the chemical structure of the modified $\mathbf{1}$ is principally a graft polymer having short oligosiloxane chains as grafts.

Table II shows the results of DSC measurements. By the addition of $\mathbf{3}$ a $T_{\mathrm{m}}$ peak dis- appeared and $T_{\mathrm{g}}$ decreased with an increase in $\mathbf{3}$ added. It was found that the membranes were plasticized by converted $\mathbf{3}$ and $\mathbf{3}^{\prime}$ which exist as grafts and additives in the membranes, respectively.

\section{Improvement of Oxygen Permselectivity}

Figure 1 shows the oxygen permeation behavior as a function of the content of 3 . Though in general $\alpha$ decreases with increasing siloxane content, in these results $\alpha$ increased with increasing 3 content $(0-20 \mathrm{~mol} \%)$. This unusual behavior might be because 3 changed

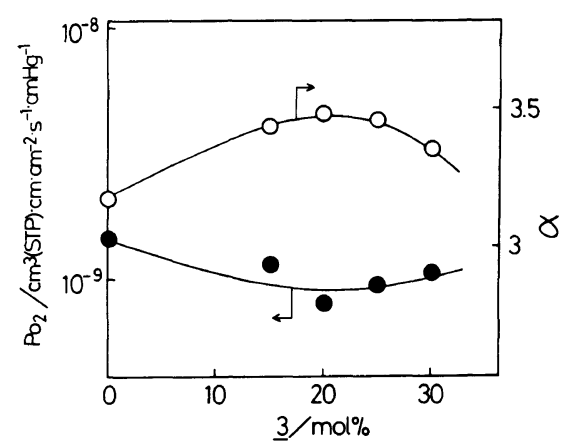

Figure 1. Effect of 3 content on the oxygen permeation behavior through the membrane modified with 3 .

Table III. Oxygen permeation behavior through the polyamide membranes

\begin{tabular}{|c|c|c|c|c|c|c|c|c|}
\hline \multirow{2}{*}{ Membrane $^{\mathrm{a}}$} & $3^{b}$ & \multirow{2}{*}{$\mathrm{Si} \%^{\mathrm{c}}$} & $P_{\mathrm{O}_{2}}^{\mathrm{d}}$ & \multirow{2}{*}{$\alpha$} & $D_{\mathrm{O}_{2}}^{\mathrm{e}}$ & \multirow{2}{*}{$D_{\mathrm{O}_{2}} / D_{\mathrm{N}_{2}}$} & $S_{\mathrm{O}_{2}}{ }^{\mathrm{f}}$ & \multirow{2}{*}{$S_{\mathrm{O}_{2}} / S_{\mathrm{N}_{2}}$} \\
\hline & $\mathrm{mol} \%$ & & $\times 10^{-9}$ & & $\times 10^{-8}$ & & $\times 10^{-2}$ & \\
\hline $1^{\mathrm{g}}$ & 0 & 35.0 & 2.34 & 3.19 & 15.7 & 1.37 & 1.49 & 2.31 \\
\hline 2 & 15 & 39.3 & 1.45 & 3.44 & 7.12 & 1.46 & 2.04 & 2.34 \\
\hline 4 & 20 & 40.6 & 0.885 & 3.48 & 5.21 & 1.50 & 1.69 & 2.31 \\
\hline 5 & 25 & 41.8 & 0.956 & 3.43 & 6.24 & 1.41 & 1.53 & 2.42 \\
\hline 6 & 30 & 43.0 & 1.02 & 3.35 & 8.96 & 1.48 & 1.14 & 2.27 \\
\hline 7 & 30 & 43.5 & 0.861 & 3.51 & 4.87 & 1.56 & 1.79 & 2.24 \\
\hline 9 & 15 & 39.3 & 1.01 & 3.02 & 6.29 & 1.26 & 1.61 & 2.41 \\
\hline $10^{\mathrm{h}}$ & - & 15.6 & 2.04 & 2.73 & - & - & - & - \\
\hline
\end{tabular}

a Numbers correspond to those in Table I.

b The ratio of $\mathbf{3}$ added to $\mathbf{1}$ or $\mathbf{2}$ based on a monomer unit.

c Means weight $\%$ of dimethylsiloxane units in the membrane.

d In $\mathrm{cm}^{3}$ (STP) $\mathrm{cm} \mathrm{cm}^{-2} \mathrm{~s}^{-1} \mathrm{cmHg}^{-1}$.

e In $\mathrm{cm}^{2} \mathrm{~s}^{-1}$

f $\mathrm{cm}^{3}$ (STP) $\mathrm{cm}^{-3} \mathrm{cmHg}^{-1}$.

g Measured using cross-linked polydimethylsiloxane as a support membrane.

${ }^{\text {h }}$ Reference 4. 
some part of crytalline region (impermeable region) to amorphous region (permeable region), in other words, more parts of the region consisting of pyridine units, which may have high oxygen permselectivity, ${ }^{5}$ became to take part in permeable region compared with the case of 1 without 3. This hypothesis is supported by the fact that $\mathrm{Tm}$ of the polyamide disappeared by adding 3 (Table III). The change of $\alpha$ was analogous to that of $D_{\mathrm{O}_{2}} / D_{\mathrm{N}_{2}}$ (Table III). With increasing siloxane content $(20-30 \mathrm{~mol} \%) \alpha$ decreased. The behavior is general ${ }^{6}$ and due to plasticization.

In conclusion, the membrane processability of the polyamide containing oligosiloxane was enhanced by treating with 1,5-dichlorohexamethyltrisiloxane. The improvement was due to both the enhancement of the molecular weight by the reaction of 1,5-dichlorohexamethyltrisiloxane with the polyamides and the plasticization by the converted 1,5-dichlorohexamethyltrisiloxane, which exists as grafts and additives in the membrane. Moreover, the modified polyamides were soluble and $\alpha$ of them increased. 1,5-Dichlorohexamethyltrisiloxane is expected to be a processabilityenhancing agent and a permselectivity-controlling agent for membranes of other brittle oligosiloxane-containing polyamides.

\section{REFERENCES}

1. E. Oikawa and H. Nozawa, Polym. Bull., 13, 481 (1985).

2. E. W. Bennett, U.S. Patent, 3,646,090 (1972).

3. Y. Kawakami, T. Aoki, and Y. Yamashita, Polym. J., 18, 243 (1986).

4. T. Kiyotsukuri, N. Tsutsumi, K. Ayama, and M. Nagata, J. Polym. Sci., A, 25, 1591 (1987).

5. M. Kawakami, Y. Yamashita, M. Iwamoto, and S. Kagawa, J. Membrane Sci., 19, 249 (1984).

6. Y. Kawakami, H. Karasawa, T. Aoki, Y. Yamamura, H. Hisada, and Y. Yamashita, Polym. J., 17, 1159 (1985); Y. Kawakami, H. Kamiya, and Y. Yamashita, J. Polym. Sci., Polym. Symp., 74, 291 (1986). 